\section{The Effects of Temperature on Lung Function}

\section{To the Editor:}

We read with great interest the extremely informative and well-written paper recently published in this Journal by Cid-Juárez and colleagues, ${ }^{1}$ in which the authors suggest that inspiratory capacity in healthy people at 2,240 $\mathrm{m}$ above sea level was higher than that of previous reports in European and Latin-American subjects of the same height, sex, and age who were at sea level. Their study provided robust reference values for persons who live at a moderate altitude. In the univariate analysis, height, weight, body mass index, and body surface area proved to be significantly associated with inspiratory capacity, whereas age, height, weight, and body surface area were significantly associated with vital capacity.

Although various baseline characteristics were considered in their study, the influence of temperature was not. However, it is well known that a decrease in ambient temperature is associated with decline in lung function. ${ }^{2,3}$ Lungs are open to the environment and are susceptible to cold air stimulation. Clinical studies suggest that inhaled cold air causes pathophysiological responses such as vasoconstriction in the respiratory tract mucosa, which may contribute to coldrelated respiratory diseases. ${ }^{4}$ Exposure to cold temperatures is an important public health concern, particularly for those with cardiorespiratory diseases. ${ }^{5}$ In addition, Mann et $\mathrm{al}^{6}$ found that increases in ambient temperature during the summer were associated with reduced peak expiratory flow

The authors have no conflicts of interest to disclose.

Correspondence to: GuanYang Kang MD, Department of Cardiology, The Fifth People's Hospital of Dongguan, The Dongguan Affiliated Hospital of Medical College of Jinan University. 111, Humen Road, Humen, Dongguan 523905, Guandong, China. E-mail: gykang2008@126.com.

DOI: $10.4187 /$ respcare. 07263 and increased frequency of respiratory tract infection. A cohort study in the United States reported that warmer temperatures were associated with lower $\mathrm{FEV}_{1}$ values in subjects with cystic fibrosis. ${ }^{7}$ Hales et al ${ }^{8}$ found that warmer temperatures were associated with increased prevalence of asthma in adults. Similar findings have been reported that each $5^{\circ} \mathrm{C}$ higher previous-week temperature was associated with a $20 \mathrm{~mL}$ lower FEV $1 .{ }^{9}$ There was significant effect modification by season: negative associations of temperature and lung function were present in winter and spring only. Negative associations between the previous day's fine particulate matter and lung function were present during unseasonably warm days but not during unseasonably cool days. The authors speculated that temperature-related differences in lung function may be explained by behavioral changes on relatively warm days, which may increase outdoor exposures. ${ }^{9}$ Therefore, temperature should be controlled for studies in which lung function is measured. We are surprised that this potentially important confounder was not considered, despite the known change in temperature with increasing altitude. Ambient conditions when lung function values were taken are not described in more detail in the study by Cid-Juárez and colleagues. ${ }^{1}$ Thus, depending on local conditions, such as altitude, weather, and time of day, and whether measurements were taken indoors or outdoors, a broad range of temperatures are conceivable. Accurately measuring lung function, at any temperature, is of great importance for studies of inspiratory capacity and vital capacity.

In our opinion, the inclusion of ambient temperature would have added value to the authors' research. If these data had been recorded, it would be of utmost interest to consider this factor in the univariate analysis to evaluate the potential contribution to lung function. Such knowledge would not only reinforce the clinical relevance of temperature effects on lung function but also enable preventive recommendations.

GuanYang Kang

Department of Cardiology

The Fifth People's Hospital of Dongguan
The Dongguan Affiliated Hospital of Medical College of Jinan University Dongguan, Guangdong, China

HuiQing Zhang

Department of Pharmacy

The Fifth People's Hospital of Dongguan

The Dongguan Affiliated Hospital of Medical College of Jinan University Dongguan, Guangdong, China

\section{REFERENCES}

1. Cid-Juárez S, Thirión-Romero I, TorreBouscoulet L, Gochicoa-Rangel L, MartínezBriseño D, Hernández-Paniagua IY, et al. Inspiratory capacity and vital capacity of healthy subjects 9-81 years of age at moderate-high altitude. Respir Care 2019;64(2):153-160.

2. Donaldson GC, Seemungal T, Jeffries DJ, Wedzicha JA. Effect of temperature on lung function and symptoms in chronic obstructive pulmonary disease. Eur Respir J 1999; 13(4):844-849.

3. Li S, Baker PJ, Jalaludin BB, Marks GB, Denison LS, Williams GM. Ambient temperature and lung function in children with asthma in Australia. Eur Respir J 2014;43(4): 1059-1066.

4. Mourtzoukou EG, Falagas ME. Exposure to cold and respiratory tract infections. Int $\mathrm{J}$ Tuberc Lung Dis 2007;11(9):938-943.

5. Carder M, McNamee R, Beverland I, Elton R, Cohen GR, Boyd J, et al. The lagged effect of cold temperature and wind chill on cardiorespiratory mortality in Scotland. Occup Environ Med 2005;62(10):702-710.

6. Mann M, Patel K, Reardon JZ, Goldstein M, Godar TJ, ZuWallack RL. The influence of spring and summer New England meteorologic conditions on the respiratory status of patients with chronic lung disease. Chest 1993;103(5):1369-1374.

7. Collaco JM, McGready J, Green DM, Naughton KM, Watson CP, Shields T, et al. Effect of temperature on cystic fibrosis lung disease and infections: a replicated cohort study. PLoS One 2011;6(11):e27784.

8. Hales S, Lewis S, Slater T, Crane J, Pearce N. Prevalence of adult asthma symptoms in relation to climate in New Zealand. Environ Health Perspect 1998;106(9):607-610.

9. Rice MB, Li W, Wilker EH, Gold DR, Schwartz J, Zanobetti A, et al. Association of outdoor temperature with lung function in a temperate climate. Eur Respir J 2019;53(1): 1800612. 